\title{
Variability in surface-subsurface hydrologic interactions and implications for nutrient retention in an arid-land stream
}

\author{
C. Lisa Dent, ${ }^{1}$ Nancy B. Grimm, ${ }^{2}$ Eugènia Martí, ${ }^{3}$ Jennifer W. Edmonds, ${ }^{4}$ \\ Julia Curro Henry, ${ }^{2}$ and Jill R. Welter ${ }^{5}$ \\ Received 13 April 2007; revised 2 July 2007; accepted 3 August 2007; published 18 October 2007.
}

[1] Hydrologic interactions among biogeochemically active stream subsystems affect material export downstream. We combined a conservative tracer addition with measurements of water table elevation and nutrient concentrations of surface and subsurface water to examine hydrologic interactions among surface and subsurface subsystems and their implications for stream biogeochemistry. We injected bromide $\left(\mathrm{Br}^{-}\right)$ into a 400-m reach of Sycamore Creek, a losing stream in central Arizona, for $15 \mathrm{~d}$ and monitored changes in concentration in three subsystems: surface, parafluvial, and riparian zones. Additionally, we collected water samples from these subsystems for nutrient analyses. Water flowed from surface to subsurface zones as expected in this losing stream, but a significant amount of subsurface water (17\% of surface discharge in the reach) returned to the surface. Within the parafluvial subsystem, median transport time $\left(\mathrm{T}_{\mathrm{med}}\right)$ in two gravel bars differed substantially (from 2 to $30 \mathrm{~h}$ and from 6 to $>300 \mathrm{~h}$, respectively, for upper and lower bars), and varied significantly with depth in the lower bar (mean $( \pm$ se) $\mathrm{T}_{\text {med }}=190 \pm 20 \mathrm{~h}$ at $30 \mathrm{~cm}$ compared to $101 \pm 18 \mathrm{~h}$ at $110 \mathrm{~cm}$ ). Flow paths from the surface to parafluvial and riparian zones, and subsequently back to the surface stream, differ from patterns in mesic areas, where water moves laterally and vertically towards the surface stream. Estimates of nutrient retention for the stream reach varied four fold in response to simulated changes in lateral subsurface connections and the configuration of subsystems. Thus at this scale, accurate nutrient budgets require an understanding of surface-subsurface connections and hydrologic parameters.

Citation: Dent, C. L., N. B. Grimm, E. Martí, J. W. Edmonds, J. C. Henry, and J. R. Welter (2007), Variability in surface-subsurface hydrologic interactions and implications for nutrient retention in an arid-land stream, J. Geophys. Res., 112, G04004, doi:10.1029/2007JG000467.

\section{Introduction}

[2] Streams are no longer considered well-mixed reactors that process and transport materials in a uniform manner along their length. Rather, it is widely acknowledged that streams are heterogeneous ecosystems consisting of interacting subsystems [Findlay, 1995; Palmer and Poff, 1997; Fisher et al., 1998a, 1998b; Wiens, 2002]. Subsystems (referred to as patches by landscape ecologists) are spatial units that are relatively homogeneous with respect to some characteristic of interest. In streams, subsystems differ in their capacity to transform and transport materials owing to variation in their biogeochemical and hydrologic character-

\footnotetext{
${ }^{1}$ Deceased 11 July 2002

${ }^{2}$ School of Life Sciences, Arizona State University, Tempe, Arizona, USA.

${ }^{3}$ Centre d'Estudis Avançats de Blanes (CSIC), Blanes, Spain.

${ }^{4}$ Department of Marine Sciences, University of Georgia, Athens, Georgia, USA.

${ }^{5}$ College of St. Catherine, Saint Paul, Minnesota, USA.

Copyright 2007 by the American Geophysical Union. 0148-0227/07/2007JG000467\$09.00
}

istics [Lewis et al., 2007]. As water moves downstream with its dissolved and suspended load, it traverses a sequence of subsystems, the collective activity of which ultimately determines the form and amount of materials exported to downstream ecosystems [Fisher et al., 1998a; Dent and Grimm, 1999].

[3] Knowledge of hydrologic connections among subsystems is essential to understanding their biogeochemical dynamics. Connections among subsystems occur in three spatial dimensions: longitudinal, lateral and vertical [Ward, 1989]. Longitudinal connections link subsystems in an upstream to downstream direction, most obviously in stream surface water but also in subsurface sediment. Lateral connections link the surface stream to the parafluvial zone (sediment and subsurface water adjacent to surface water within the active channel), the riparian zone (the area between the active channel and the hillslope, with longerlived vegetation), and upland regions, mostly through surface-subsurface water exchange. Vertical connections link surface water with the subsurface sediment in hyporheic zones (subsurface sediment and water directly underneath the wetted channel). Vertical connections also link subsurface sediment in both parafluvial and hyporheic 
zones with more distant groundwater. In this paper we consider three subsystems: parafluvial and hyporheic zones treated as a single subsystem (hereafter, parafluvial gravel bars), riparian, and surface stream subsystems (see Holmes et al. [1994a, 1994b] and Martí et al. [2000] for further details on these subsystems).

[4] The strength, location and direction of hydrologic exchange among subsystems affect flow paths and rates of material transport, and thereby influence whole-reach nutrient processing and retention [Fisher et al., 1998a]. However, despite the apparent importance of subsystem configuration to stream material processing, few studies document hydrologic connections among surface water, active-channel sediment, and the riparian zone, particularly for the predominantly losing streams common in arid lands. Lateral movement of water is likely to differ between streams in mesic and arid regions [Fetter, 1994]. In mesic areas, rainfall infiltrates upland soils and moves downslope to enter the stream laterally, thus the dominant direction of lateral movement of water is from the uplands toward the stream. In arid areas, impervious soils cause most rainfall to flow overland, entering the stream through a network of rills and tributaries [Fetter, 1994]. Floodwater then moves from the stream channel out to parafluvial and riparian zones via subsurface flow paths [Marti et al., 2000; Butturini et al., 2003]. This dominant direction of lateral movement may persist even between storms, especially when evapotranspiration is high, but this assumption has not been tested.

[5] Within these broad-scale patterns of water movement, local variation in slope and sediment characteristics may create complex flow paths in both losing and gaining streams [Harvey and Bencala, 1993; Wondzell and Swanson, 1996; Pinay et al., 1998; Butturini et al., 2003; Gooseff et al., 2007]. In long, broad runs typical of many streams in the U.S. Southwest, apparent uniformity of sediment size and distribution leads to the untested conclusion that subsurface hydrologic characteristics, such as velocity and flow direction, are also uniform. This assumption may be particularly unwarranted with respect to vertical variation, yet virtually nothing is known of variance in subsurface flow characteristics with depth.

[6] Biogeochemical processes alter the form and amount of materials, such as nutrients, transported through and among stream subsystems. Small-scale studies have described changes in water chemistry that occur along flow paths in different subsystems. For example, Gucker and Boechat [2004] showed that ammonium uptake in different subreaches of a tropical headwater stream was positively related to the amount of water in transient storage zones. In Sycamore Creek, Arizona, mineralization of organic matter led to increased concentrations of nitrate-nitrogen $\left(\mathrm{NO}_{3}-\mathrm{N}\right)$ and soluble reactive phosphorus (SRP) along hyporheic and parafluvial flow paths [Holmes et al., 1994b; Jones et al., $1995 \mathrm{a}]$. In contrast, $\mathrm{NO}_{3}-\mathrm{N}$ declines along most riparian flow paths en route to streams [e.g., Hill et al., 2000; Clement et al., 2003; McClain et al., 2003]. The contribution of such small-scale $(<10 \mathrm{~m})$ changes in nutrient concentration to biogeochemistry at the reach scale (hundreds of meters) depends on the pattern of hydrologic interaction among subsystems at that larger scale. Knowledge of nutrient pool sizes and hydrologic characteristics of different subsystems, and of linkages among those subsys- tems, allows inference about whole-system nutrient retention (defined as the difference between hydrologic input and output of a nutrient).

[7] In this study we combined measurements of water table elevation and nutrient concentrations of surface and subsurface water with long-term addition of a conservative hydrologic tracer (bromide, $\mathrm{Br}^{-}$) to identify paths of water movement within and among subsystems and examine the implications of the hydrological exchanges on whole reach nutrient retention. The study was conducted in a $400-\mathrm{m}$ reach of Sycamore Creek, a losing stream in central Arizona. We injected $\mathrm{Br}^{-}$into stream surface water for $15 \mathrm{~d}$ while monitoring changes in $\mathrm{Br}^{-}$concentration in the three subsystems. Our study was organized around three questions:

[8] 1. How does water move among subsystems at baseflow? We used results from the $\mathrm{Br}^{-}$addition and measured hydraulic gradients to determine the extent of surfacesubsurface hydrologic interaction.

[9] 2. How does the extent and rate of surface-subsurface exchange vary within subsystems? Here we focused on the parafluvial zone, where we installed grids of nested piezometers that sampled three depths in two gravel bars.

[10] 3. What are the implications of surface-subsurface interactions for nutrient retention in the stream?

[11] Our study utilized a much longer injection time than most similar studies [cf. Triska et al., 1989], which allowed us to identify hydrological connections between surface water and distal riparian areas. We expected that the overall direction of water movement in this losing stream would be from the surface stream to the parafluvial zone to the riparian zone, with few inputs of subsurface water outside these subsystems (i.e., from uplands). Within channel sediment, we expected hydrologic parameters like median transport time and velocity to vary little because sediment appears to be relatively homogeneous. Finally, we expected that nutrient concentrations in these subsystems would reflect differences in dominant processes (uptake for surface; mineralization for channel sediment; denitrification for riparian) coupled with time available for processing (i.e., residence time). Based on small-scale studies in the hyporheic and parafluvial zones of Sycamore Creek [e.g., Holmes et al., 1994b; Jones et al., 1995a], our null hypothesis was that nutrient concentrations would increase with water residence time along subsurface flow paths. Most of our expectations were met, except that we found substantial variation in median transport time both longitudinally and with depth in the parafluvial zone and longitudinally in the riparian zone. Associated with this hydrologic heterogeneity, nutrient concentrations and the potential for nutrient retention could vary several fold.

\section{Site Description}

[12] This study was done in Sycamore Creek, a midsized, spatially intermittent stream located in the northern Sonoran Desert of central Arizona (United States). The stream drains a $505-\mathrm{km}^{2}$ watershed of mountainous terrain with elevations ranging from 425 to $>2,000 \mathrm{~m}$. Overall Sycamore Creek is a losing stream; specific reaches may be gaining or losing but this can vary temporally. We selected a $400-\mathrm{m}$ reach $(585 \mathrm{~m}$ elevation; $\left.33^{\circ} 43^{\prime} 06^{\prime \prime} \mathrm{N}, 111^{\circ} 31^{\prime} 33^{\prime \prime} \mathrm{W}\right)$, which was the site of 

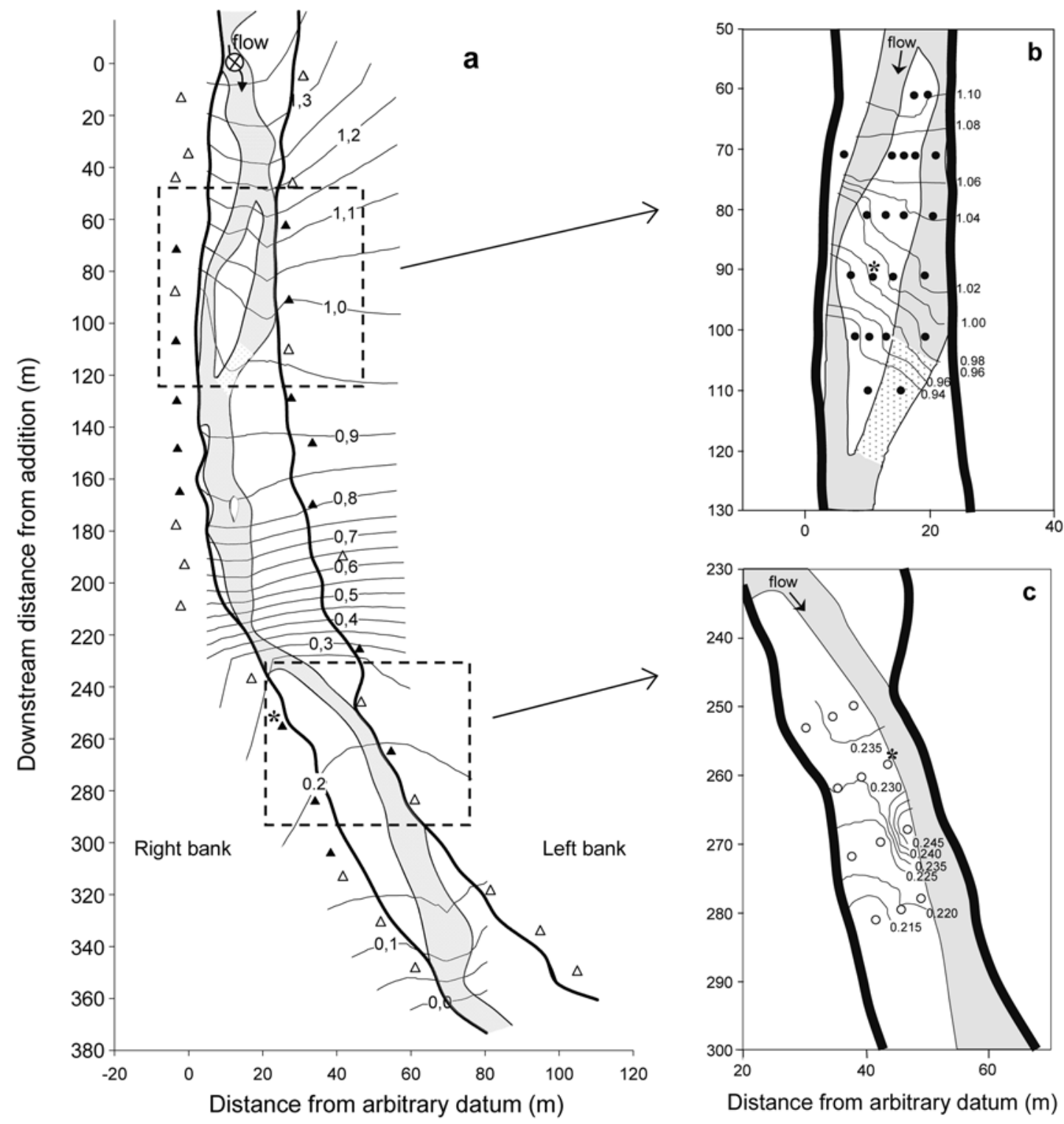

Figure 1. (a) Planimetric map of the study area. Note that the horizontal scale has been exaggerated to clarify the lateral dimension. Water flows top to bottom from the addition point $(0 \mathrm{~m}$, indicated by encircled cross). Bold lines delineate the active channel, shaded areas indicate surface water, and the unshaded area is the parafluvial zone (within active channel) or riparian zone (outside active channel). The stippled area from $\mathrm{m} \mathrm{120-140} \mathrm{is} \mathrm{the} \mathrm{portion} \mathrm{of} \mathrm{the} \mathrm{side} \mathrm{channel} \mathrm{that} \mathrm{dried} \mathrm{during} \mathrm{the} \mathrm{experiment.}$ Piezometers in the riparian zone (triangles) were distributed along the 400-m study reach. The subset of riparian piezometers that was sampled for water chemistry is denoted by solid triangles. Contour lines were interpolated from stage height measured every $10 \mathrm{~m}$ above an arbitrary point and from water table elevation in shallow piezometers, but are not available for the riparian zone. Boxed portions of the study area are expanded in (b) upper gravel bar and (c) lower gravel bar, showing locations of parafluvial piezometer nests (solid circles for upper bar, open circles for lower bar). Contour lines in Figures $1 \mathrm{~b}$ and 1c are from water table elevations in shallow gravel-bar wells, in reference to an arbitrary point. Subsurface flow paths are perpendicular to these contours. $\mathrm{Br}-$ breakthrough curves for piezometers indicated with asterisks are shown in Figure 2.

numerous other studies [e.g., Holmes et al., 1994b, 1996; Jones et al., 1995b; Marti et al., 2000] (Figure 1a). Here the active channel was $20-25 \mathrm{~m}$ wide with a substratum dominated by coarse sand that averaged $1 \mathrm{~m}$ in depth [Holmes et al., 1994b]. Average channel slope of the reach was $0.4 \%$, but channel gradient increased midway through the reach $(200-260 \mathrm{~m})$, and sediment size also increased from coarse sand to pebbles and small cobbles. The surface stream was 3-10 m wide, 5-16 cm deep, and meandered across the active channel. Location of surface water is a 

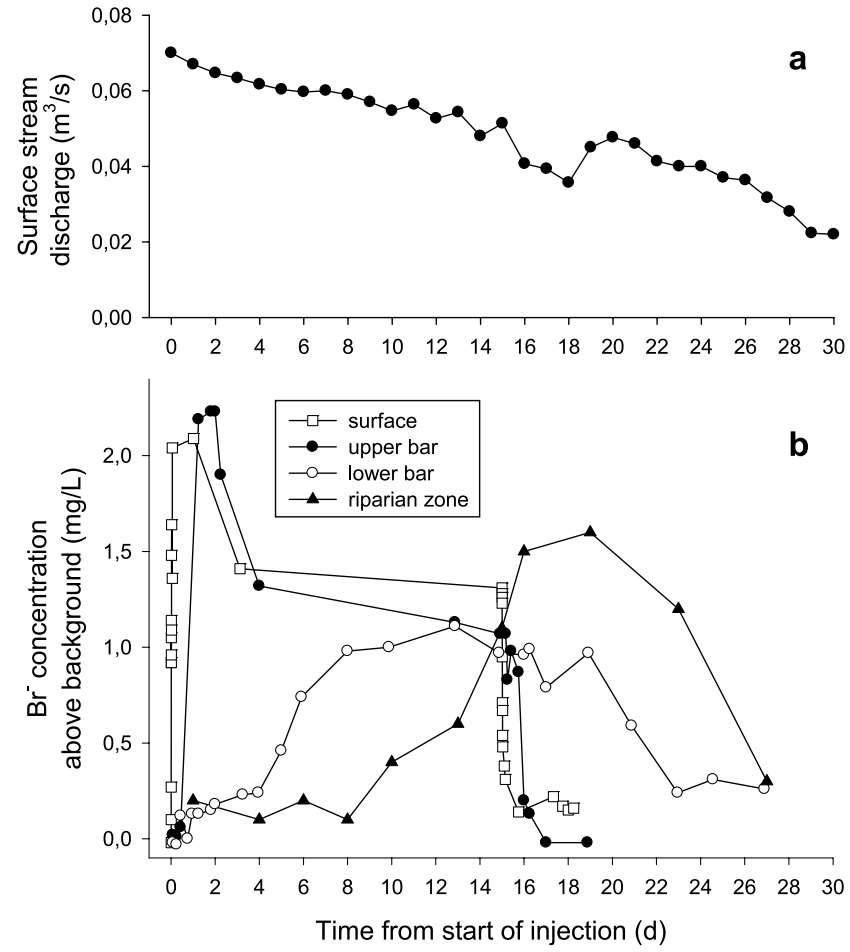

Figure 2. Three-day running average of discharge in the surface stream (a) and background-corrected $\mathrm{Br}^{-}$breakthrough curves (b) at representative locations from each subsystem (surface water, upper gravel bar, lower gravel bar, and riparian zone) over the course of the study. The injection ended on day 15. Surface-water data are from $\mathrm{m}$ 120 for the increase (day 0-4) and from $\mathrm{m} 150$ for the decrease (day 15-19), and riparian data are from a piezometer at $260 \mathrm{~m}$ (see Figure 1). Data for both gravel bars are from the $70-\mathrm{cm}$ piezometer at locations indicated in Figure 1.

dynamic feature of gravel-bedded, arid-land streams like Sycamore Creek, which are subject to frequent sediment rearrangement by flash floods followed by drying of surface water. Sediment-surface elevation rose abruptly at the transition from the active channel to the riparian zone, which averaged $14 \mathrm{~m}$ in width on each side. In the riparian zone, organic matter and fine-sediment accumulations characterized the upper soil layer (to $\sim 30 \mathrm{~cm}$ ), whereas riverine deposits of cobbles and boulders occurred in deeper layers.

[13] The Sonoran Desert exhibits two distinct rain seasons during which stream discharge often increases rapidly in response to single events; winter rains characterized by frontal storms and the summer monsoon with isolated, convective storm cells. Winter floods typically are followed by several months of little precipitation, during which stream discharge declines exponentially. This study started on 1 May 1997, 2 months after the last winter flood of the season (28 February), and discharge decreased from $66 \mathrm{~L} / \mathrm{s}$ on 1 May to $18 \mathrm{~L} / \mathrm{s}$ by the final sampling day of 2 June (Figure 2a). Decrease in discharge was also noticeable in the gradual drying of a surface side channel, located at the upper part of the reach (m 50-120, Figure 1a), over the course of the study.
[14] Algal communities in the surface stream were typical of late-spring successional stages, and were dominated by diatoms and the filamentous chlorophyte, Cladophora glomerata. Mean standing crop of algae reached $>200 \mathrm{mg}$ chlorophyll $\mathrm{a} / \mathrm{m}^{2}$ on 13 May 1997. Gravel bars, which comprise that portion of the active channel lacking surface water flow (i.e., parafluvial zone), were largely free of vegetation. Only a few stems of Baccharis developed at the gravel bar next to the side channel. The riparian zone along the reach hosted a well developed vegetation community typical of the Upper Sonoran life zone, described in more detail by Schade et al. [2002, 2005].

[15] Previous studies in Sycamore Creek have found that nitrogen $(\mathrm{N})$ limits primary production in the surface stream during baseflow [Grimm and Fisher, 1986]. Subsurface water flowing through the channel sediment is usually oxygenated and supports high rates of respiration (11.9 g $\mathrm{O}_{2} \mathrm{~m}^{-2} \mathrm{~d}^{-1}$ [Jones et al., 1995b]) and nitrification $(0.2 \mathrm{~g}$ $\mathrm{NO}_{3}-\mathrm{N} \mathrm{m}^{-2} \mathrm{~d}^{-1}$ [Jones et al., 1995a]). This leads to subsurface concentrations of $\mathrm{NO}_{3}-\mathrm{N}$ and SRP higher than in the surface stream [Valett et al., 1990; Holmes et al., 1994b; Holmes, 1995; Marti et al., 2000]. Exceptions to this characterization are vegetated gravel bars, which show reduced oxygen, high potential rates of denitrification, and concomitantly low concentrations of $\mathrm{NO}_{3}-\mathrm{N}$ [Schade et al., 2001]. Nutrient transformations in the riparian zone are likely more similar to those in vegetated gravel bars, as low $\mathrm{NO}_{3}-\mathrm{N}$ concentration is common and high potential rates of denitrification have been recorded [e.g., Holmes et al., 1996; Martí et al., 2000; Schade et al., 2002; Harms, 2004; Schade et al., 2005; Lewis et al., 2007].

\section{Methods}

\subsection{Instrumentation and Mapping of the Reach}

[16] The 400-m reach was mapped using a tripod, surveyor's level and telescoping rod to locate surface stream edges, gravel bars, active channel-riparian boundary, and positions of wells and piezometers placed along the reach. A total of 35 piezometers (19 on the right bank and 16 on the left bank) were placed in the riparian zone at approximately 20-m intervals along each bank of the stream, $\sim 4 \mathrm{~m}$ from the active channel boundary (Figure 1a). The piezometers were PVC tubes of $16-\mathrm{mm}$ internal diameter and $1.5-2 \mathrm{~m}$ length, screened over the lower $5 \mathrm{~cm}$ only. To install the piezometers, a T-bar ( 2 or $3 \mathrm{~m}$ in length) was inserted into the PVC tube and the assembly was driven into the riparian sediment with a sledge hammer, to a mean depth of $1.3 \mathrm{~m}$ below ground surface.

[17] Piezometers similar to those in the riparian zone were installed in the parafluvial zone on grids established in two gravel bars (referred to as upper and lower bars; Figures $1 \mathrm{~b}$ and 1c). In the upper bar, a total of 20 "nests" of piezometers were installed, each at two depths (30 and $70 \mathrm{~cm}$ below the water table) in 6 rows, and at a third depth $(110 \mathrm{~cm})$ in one of the rows (total, 47 piezometers). In the lower bar, where sediment was deeper, a total of 12 piezometer nests were installed, each at 3 depths $(30,70$, and $110 \mathrm{~cm}$ below the water table) in 4 rows, and at a fourth depth $(170 \mathrm{~cm})$ in the upstream row, for a total of 39 piezometers. Shallow parafluvial wells were screened along their entire length, enabling us to use them to determine 
water table elevations relative to an arbitrary benchmark; we refer to these as piezometers except when discussing water table depth. Deeper, nested piezometers were screened only over the lower $5 \mathrm{~cm}$.

[18] Stage height was measured at 10-m intervals along the reach on 8 April 1997, and water table depth was measured in shallow parafluvial wells on 27 April 1997. On this date, stream discharge was $70 \mathrm{~L} / \mathrm{s}$. Vertical hydraulic gradient (VHG) between a $25-\mathrm{cm}$ depth and surface water was measured every $10 \mathrm{~m}$ along the reach in the center of the stream on 15 April 1997, using mini-piezometers [Lee and Cherry, 1978]. Water table contours were interpolated for surface water (Figure 1a) and for each gravel bar (Figures 1b and 1c) using Sigmaplot (version 10), and surface and subsurface flow paths were interpreted as perpendicular to contour lines. Stream discharge was estimated once a day (at $\sim 0800 \mathrm{~h}$ ) by measuring width, depth and velocity at a single site $2 \mathrm{~m}$ above the head of the reach.

\subsection{Addition of Hydrologic Tracer}

[19] Bromide $\left(\mathrm{Br}^{-}\right)$, a conservative hydrologic tracer, was injected at a constant rate into surface water for $15 \mathrm{~d}$ beginning on 1 May 1997. A metering pump (Fluid Metering Systems $\left.{ }^{\circledR}\right)$ added the tracer solution $(700 \mathrm{~g} / \mathrm{L} \mathrm{NaBr})$ to the center of the surface stream at the head of the reach, increasing concentration by $\sim 2 \mathrm{mg} / \mathrm{L}$ over background $(0.1 \mathrm{mg} / \mathrm{L})$. After the first $20 \mathrm{~h}$ of the experiment, we lowered the concentration of the tracer solution to avoid its precipitation during the colder nighttime hours. This adjustment resulted in a concentration in surface water of about $1.8 \mathrm{mg} / \mathrm{L}$ at the first well-mixed stream station, but also produced a transitory peak in stream $\mathrm{Br}^{-}$concentration over the first few days of the experiment.

[20] Before the addition started, we collected water samples from the surface stream and the parafluvial and riparian piezometers to measure background $\mathrm{Br}^{-}$concentration. After initiating the $\mathrm{Br}^{-}$addition, we collected surface-water samples at 1-, 2-, and 5-min intervals over $100 \mathrm{~min}$ at 120 and $280 \mathrm{~m}$ until plateau conditions (i.e., indicative of complete mixing of added solution with surface water) were reached ( $<100 \mathrm{~min})$. Additional surface-water samples were collected at 20-m intervals along the reach on 1, 2, 3, 4, 6, and 16 May. Water samples from parafluvial and riparian piezometers were collected after initiation of the addition, using a battery-powered peristaltic pump, at time intervals chosen based on probable rates of water flow into these zones $(2-8 \mathrm{~h})$. When the tracer addition was stopped (16 May), water samples from the surface stream and from parafluvial and riparian piezometers were again collected at variable intervals (for the stream, $2-5$ min increasing to 6-10 h; for the subsurface zones, $2-8 \mathrm{~h}$ increasing to $1-$ 2 d) until $\mathrm{Br}^{-}$concentration declined to near background levels. We completed water sampling by 2 June. Bromide concentration was measured in all samples using a $\mathrm{Br}^{-}$specific electrode (Orion model 290A), standardized with periodic measurements of a sample of known concentration (standard). Before analysis, all samples and standards were mixed with an ionic strength adjustor, $5 \mathrm{M}$ sodium nitrate.

[21] Declines in $\mathrm{Br}^{-}$concentration along the surface stream were used to examine lateral or vertical connections from subsurface into surface water. Surface water was well mixed with added tracer $60 \mathrm{~m}$ downstream from the addition point, so we used the $60-\mathrm{m} \mathrm{Br}^{-}$plateau concentration $\left(1.8 \mathrm{mg} / \mathrm{L}, \mathrm{Br}_{60}\right)$ to estimate percentage subsurface inflow $\left(\mathrm{Q}_{\mathrm{L}}\right): Q_{L}=\left(\frac{B r_{x}}{B r_{60}}\right) \times 100$; where $\mathrm{Br}_{\mathrm{x}}$ is the plateau $\mathrm{Br}^{-}$concentration at each sampling point. We also compared longitudinal patterns of $\mathrm{Q}_{\mathrm{L}}$ between days 1 and 15 of the injection to identify changes over time. Because discharge dropped from 66 to $42 \mathrm{~L} / \mathrm{s}$ during the 15-d addition, we adjusted the d-15 pattern to a mean discharge of $66 \mathrm{~L} / \mathrm{s}$ to directly compare it to the d-1 pattern. Surface flow may decline faster than subsurface flow [Stanley and Valett, 1992], which could cause subsurface inflow to appear larger when discharge is lower.

[22] Bromide breakthrough curves at each sampling point were used to measure the extent and rate of exchange between labeled surface water and parafluvial and riparian subsurface water [Triska et al., 1989]. Extent of surfacesubsurface exchange for all piezometers was estimated as the $\mathrm{Br}^{-}$concentration at plateau in each piezometer $\left(\mathrm{Br}_{\mathrm{xi}}\right)$ relative to that of the surface at $60 \mathrm{~m} \mathrm{Br}_{60}$ (again, expressed as a percentage). Rate of hydrologic exchange was measured using the median transport time $\left(\mathrm{T}_{\text {med }}\right)$, defined as the time for tracer concentration at a given location to reach one-half of the plateau concentration [Runkel, 2002]. Most riparian piezometers did not reach steady state during the 15-d injection. Therefore, we used the highest recorded concentration (often occurring after $>15 \mathrm{~d}$ ) as the plateau value to estimate $T_{\text {med }}$ for this subsystem. For this reason, reported $\mathrm{T}_{\text {med }}$ for riparian piezometers may be underestimated. Calculation of mean water velocity (i.e., travel distance $/ \mathrm{T}_{\text {med }}$ ) within each subsystem was subjected to an estimated subsurface flow path length, based upon reach mapping.

[23] Hydrologic characteristics (i.e., extent and rate of exchange) were compared among and within subsystems using ANOVA and Tukey's multiple comparison tests. A cursory examination of the data revealed that the upper and lower gravel bars differed substantially in their hydrologic and chemical characteristics, so we treated them separately in our analysis.

\subsection{Chemical Sampling and Analysis}

[24] Water samples were collected on 2 June from the surface stream $(\mathrm{n}=14)$ and from piezometers in the upper and lower gravel bars ( $n=47$ and 39, respectively) for chemical analysis. Water samples from a subset of riparian piezometers ( $\mathrm{n}=16$; see Figure 1a) were collected on 20 May. Duplicate samples were collected at each location using a battery-powered peristaltic pump. Water samples were stored at $4^{\circ} \mathrm{C}$, filtered through Whatman $\mathrm{GF} / \mathrm{F}$ glass fiber filters upon return to the laboratory (within 4-6 h), and analyzed for nitrate- $\mathrm{N}\left(\mathrm{NO}_{3}-\mathrm{N}\right)$, soluble reactive phosphorus (SRP), dissolved organic carbon (DOC), specific ultraviolet absorbance (SUVA), and conductivity. Riparian samples were analyzed for ammonium-N $\left(\mathrm{NH}_{4}-\mathrm{N}\right)$ with the phenolhypochlorite method [Solorzano, 1969]; however, surface and parafluvial samples were not analyzed for $\mathrm{NH}_{4}-\mathrm{N}$ due to time constraints and because these subsystems are generally low in $\mathrm{NH}_{4}-\mathrm{N}$ [Grimm and Fisher, 1986; Holmes et al., 1996]. $\mathrm{NO}_{3}-\mathrm{N}$ was determined by colorimetric analysis following reduction to nitrite [Wood et al., 1967] on a Bran \& Luebbe TRAACS 8007 autoanalyzer. 

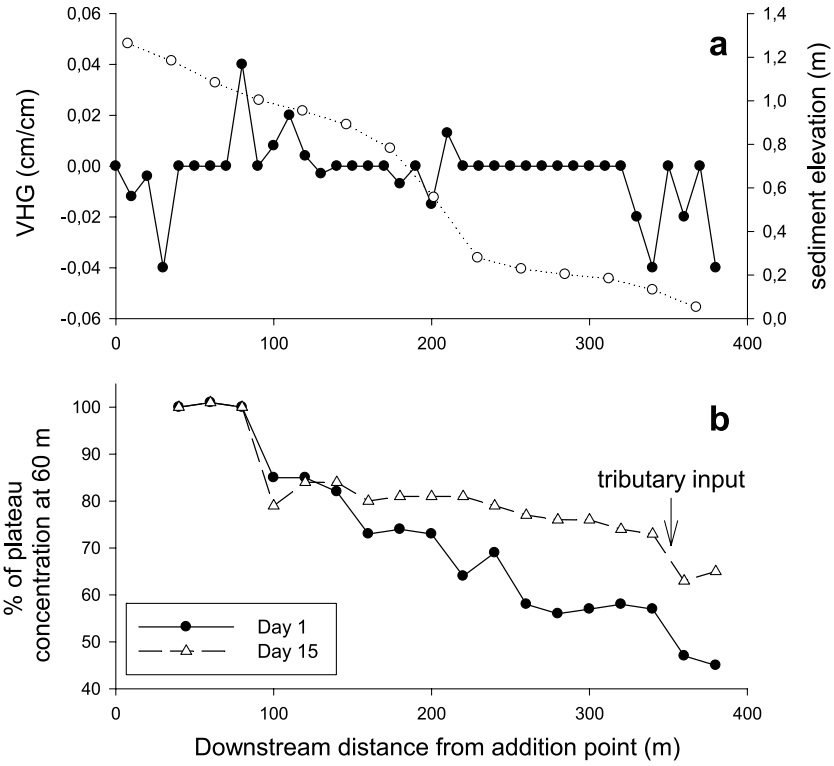

Figure 3. (a) Vertical hydraulic gradient (VHG) between surface water and $25 \mathrm{~cm}$ depth in the sediment, measured every $10 \mathrm{~m}$ (left axis), and longitudinal profile of the stream (right axis). (b) Dilution of standardized $\mathrm{Br}^{-}$tracer concentration by lateral inflow $\left(\mathrm{Q}_{\mathrm{L}}\right)$ on day 1 and day 15 of the $\mathrm{Br}^{-}$injection experiment. Day $1(\mathrm{Q}=66 \mathrm{~L} / \mathrm{s})$ pattern shown as measured; concentration pattern for day $15(\mathrm{Q}=$ $42 \mathrm{~L} / \mathrm{s}$ ) was adjusted for a $66 \mathrm{~L} / \mathrm{s}$ discharge value by assuming that changes in discharge affect surface water only and not subsurface inputs.

Some $\mathrm{NO}_{3}-\mathrm{N}$ values were below the detection limit $(1 \mu \mathrm{g} / \mathrm{L})$ and were set to $0.5 \mu \mathrm{g} / \mathrm{L}$. Molybdate-antimony analysis was used to determine SRP concentration [Murphy and Riley, 1962]. DOC was analyzed using high-temperature oxidation on a Schimadzu Total Organic Carbon Analyzer 5000. We also measured DOC chemical complexity using SUVA, which is a qualitative estimate of the number of aromatic rings per mg DOC [Korshin et al., 1997]. SUVA is the absorbance of a filtered, acidified $(6 \mathrm{~N} \mathrm{HCl})$ water sample at $245 \mathrm{~nm}$, divided by the DOC concentration in the sample. Conductivity was measured with a VWR Scientific7 conductivity meter. Analytic variability for all analyses was low, with standard deviations for replicate samples usually $<10 \%$ of mean values. Chemical characteristics were compared among and within subsystems using ANOVA and Tukey's multiple comparison tests.

\section{Results}

\subsection{Hydrologic Connections Among Subsystems}

[25] Longitudinal patterns of VHG in the surface stream, the piezometric surface of the reach, and data from the $\mathrm{Br}^{-}$ tracer experiment together indicate extensive vertical and lateral hydrologic exchange among surface stream, parafluvial and riparian subsystems. Tracer concentration reached plateau in the surface stream within $2 \mathrm{~h}$ (see Figure $2 \mathrm{~b}$ for exemplary sample location), yielding an average water velocity of $460 \mathrm{~m} / \mathrm{h}$ in this subsystem. After the initial decrease in $\mathrm{Br}^{-}$concentration due to adjustments in con- centration of added solute, the surface-water plateau at $120 \mathrm{~m}$ remained steady at about $1.5 \mathrm{mg} / \mathrm{L}$ until the addition stopped. After cessation of the $\mathrm{Br}^{-}$addition, concentration quickly decreased to background levels by $0.3 \mathrm{~h}$ at the top of the reach. Background $\mathrm{Br}^{-}$concentration in surface water upstream of the study reach rose from 0.1 to $\sim 0.4 \mathrm{mg} / \mathrm{L}$ over the course of the experiment, likely due to evaporation as discharge steadily decreased (Figure 2a). Still, $\mathrm{Br}^{-}$concentration at downstream sites remained elevated on the final sampling date $(0.6 \mathrm{mg} / \mathrm{L}$ at $250 \mathrm{~m}$ and $350 \mathrm{~m}$ compared to $0.3 \mathrm{mg} / \mathrm{L}$ at $20 \mathrm{~m}$ ), showing that $\mathrm{Br}^{-}$continued to be released from subsurface storage zones.

[26] Positive VHG indicated that subsurface water was discharging from the hyporheic zone to the surface stream (i.e., upwelling) at $\mathrm{m} 80-120$ and $\mathrm{m} 210$ corresponding to breaks in slope of the surface sediment, while negative VHG at $\mathrm{m} \mathrm{10-30,m} \mathrm{180-200,} \mathrm{and} \mathrm{m} 330-380$ indicated downwelling of surface water into the channel sediment (Figure 3a). Longitudinal decline in $\mathrm{Br}^{-}$concentration in surface water after 1 day of injection indicated that unlabeled subsurface water was entering the surface stream (Figure 3b), supporting VHG results. Major inputs (i.e., steeper declines in concentration) occurred at upwelling sites and where the subsurface water from a tributary entered the surface stream (Figure $3 \mathrm{~b}$ ). Tracer concentration was $100 \%$ of plateau in the surface stream at the top of the study reach (by definition), and declined to a value of 55\% above the tributary input (Figure $3 b$ ), yielding $Q_{L}$ for the reach of $45 \%$. Less downstream dilution of tracer was observed on d 15 of the experiment, with a shallower longitudinal decline in $\mathrm{Br}^{-}$and $\mathrm{Q}_{\mathrm{L}}$ of $28 \%$ for the reach. However, steep changes in $\mathrm{Br}^{-}$concentration indicating unlabeled subsurface inputs were still observed near the addition point and at the tributary junction (Figure 3b).

[27] Water-elevation contours identified lateral and longitudinal connections between surface water and subsurface water in the parafluvial zone (Figure 1). The upper gravel bar had a higher hydraulic gradient $(0.006 \mathrm{~m} / \mathrm{m})$ than the surface stream $(0.004 \mathrm{~m} / \mathrm{m})$. Based on these data, surface water entered the upper gravel bar at its upstream end and exited along the lower right edge of the bar (Figures $1 \mathrm{a}$ and $1 \mathrm{~b}$ ). $\mathrm{Br}^{-}$data confirmed this pattern. $\mathrm{Br}^{-}$concentration in upperbar piezometers reached plateau within 24-30 h (e.g., Figure $2 b$ ), indicating rapid infiltration of surface water. Once in the gravel bar, subsurface water moved down the gradient, generally parallel to the longitudinal axis of the channel. Estimated $\mathrm{T}_{\text {med }}$ increased with distance from the upstream end of the gravel bar, ranged between 2 and $30 \mathrm{~h}$, and averaged $19 \mathrm{~h}$ (median $=11 \mathrm{~h}$ ). Water velocities calculated based on this presumed flow path and $\mathrm{T}_{\text {med }}$ were relatively high $(2.5-3 \mathrm{~m} / \mathrm{h})$. Plateau $\mathrm{Br}^{-}$concentration in the upper gravel bar was $49 \%$ of surface-water plateau at the top of the bar, rising to $68 \%$ at the downstream end (Figure 4a). Once addition was stopped, $\mathrm{Br}^{-}$returned to near background concentration within 4-92 h (mean = $25 \mathrm{~h}$ ).

[28] Hydraulic gradient in the lower gravel bar was shallower $(0.0008 \mathrm{~m} / \mathrm{m})$ than that of the upper gravel bar (Figure 1c versus Figure 1b). Water-elevation contours indicated longitudinal subsurface flow, but also showed a point of strong surface-water infiltration into the bar at about $\mathrm{m}$ 270-280 (Figure 1c). At the 280-m piezometer 

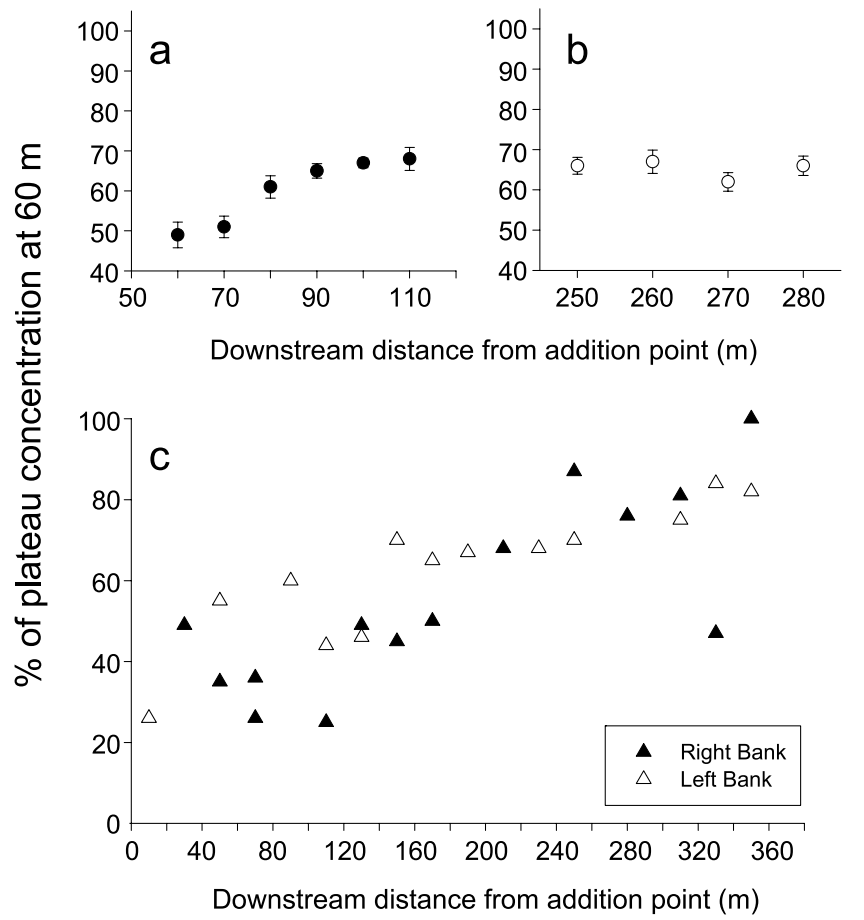

Figure 4. Dilution of tracer by "lateral inputs" $\left(\mathrm{Q}_{\mathrm{L}}\right)$ on day 15 of the injection experiment for subsurface subsystems: parafluvial zone/upper (a) and lower (b) gravel bars, and riparian zone (c). Tracer concentrations were standardized by dividing by the concentration at the most upstream, well-mixed, surface-stream point (m 60). Upperand lower-bar values are mean of all piezometers at each downstream distance. Riparian piezometers on right and left bank are shown separately.

nest, $\mathrm{Br}^{-}$data confirmed that all depths were highly connected with the stream $\left(\mathrm{T}_{\text {med }}=7,10\right.$, and $19 \mathrm{~h}$ for shallow, medium, and deep piezometers, respectively). Increase in $\mathrm{Br}^{-}$concentration in this gravel bar was slower than that in the surface stream and upper bar (Figure 2b), with a wide range in $\mathrm{T}_{\text {med }}$ from 7 to $>312 \mathrm{~h}$ (mean $124 \mathrm{~h}$ or $5.2 \mathrm{~d}$; median $120 \mathrm{~h}$ ), but all piezometers became labeled. Subsurface water velocities showed a narrow range (i.e., $0.05-0.4 \mathrm{~m} / \mathrm{h}$ ) and were much lower than those of the upper gravel bar. In this gravel bar, plateau concentrations were consistently about $65 \%$ of surface-water plateau (Figure $4 b$ ). After the addition stopped, $\mathrm{Br}^{-}$concentration declined to near background within $2-17 \mathrm{~d}$.

[29] All riparian piezometers were labeled by the end of the experiment, indicating both lateral connections with surface and subsurface water from the active channel as well as longitudinal subsurface flow within the riparian zone. Median transport time ranged from at least 4 to $19 \mathrm{~d}$, and indicated localized entry of stream water into the riparian zone (i.e., locations with low $\mathrm{T}_{\text {med }}$ in Figure 5). For these piezometers, assuming a direct flow path from the nearest surface-stream location, water velocity would range from 0.1 to $0.3 \mathrm{~m} / \mathrm{h}$. Maximum $\mathrm{Br}^{-}$concentration in riparian piezometers increased steadily in a downstream direction from approximately $25 \%$ of surface-water plateau at the top of the reach to about $80 \%$ at the bottom (Figure $4 \mathrm{c}$ ). $\mathrm{Br}^{-}$concentration slowly declined towards background levels by $12 \mathrm{~d}$ after the injection ended.

\subsection{Hydrologic Variation Within the Parafluvial Subsystem}

[30] In addition to hydrological differences among subsystems described above, we examined data from nested piezometers to determine differences within the gravel bars in surface-subsurface connections and subsurface flow paths. Within the upper bar, shallow, medium and deep piezometers did not differ significantly in $\mathrm{T}_{\text {med }}$ (Figure 6), nor did disappearance of tracer from piezometers after injection shutoff vary by depth. However, in the lower bar, excluding the piezometer nest at $280 \mathrm{~m}$ that was highly connected to the surface stream, there were significant differences in $T_{\text {med }}$ among depths (Figure 6; one-way ANOVA, $\mathrm{F}=5.53, \mathrm{p}=0.009, \mathrm{df}=2,31$ ).

[31] Tracer movement at each depth in the lower bar followed water table isoclines, but deep and medium piezometers were labeled before shallow ones in nearly all cases (e.g., a pattern like those in Figures $7 \mathrm{a}$ and $7 \mathrm{~b}$ ). For example, in piezometers near the riparian edge, deep piezometers were labeled first, followed by medium and then shallow piezometers. Thus, $T_{\text {med }}$ of the four $30-\mathrm{cm}$ depth piezometers along the riparian edge of the lower bar was nearly twice that of the four corresponding $110-\mathrm{cm}$ piezometers (means $=9.8 \mathrm{~d}$ versus $5 \mathrm{~d}$, respectively). Tracer disappearance from most piezometers in the lower bar occurred first from deep piezometers, then medium, then shallow ones (Figures 7a and 7b). However, the $\mathrm{Br}^{-}$curves for one piezometer nest on the stream side of the lower bar did not differ with depth (Figure 7c), and the shallow depth in the piezometer nest at $280 \mathrm{~m}$ (discussed earlier) was labeled very rapidly (Figure 7d).

\subsection{Comparison of Water Chemistry Among and Within Subsystems}

[32] Concentration of $\mathrm{NO}_{3}-\mathrm{N}$ differed significantly among the surface stream, upper bar, lower bar, and riparian zone (Table 1). Riparian $\mathrm{NO}_{3}-\mathrm{N}$ concentration was similar to that in surface water (between 12 and $14 \mu \mathrm{g} / \mathrm{L}$ ), but $\mathrm{NH}_{4}-\mathrm{N}$ concentration was high $(32+7 \mu \mathrm{g} / \mathrm{L})$ compared to a typical surface-water concentration of $<10 \mu \mathrm{g} / \mathrm{L}$ [Grimm and Fisher, 1986; Holmes et al., 1996]. SRP concentration was low in surface, upper bar and riparian zone (from 13 to $27 \mu \mathrm{g} / \mathrm{L}$, compared to a long-term average for Sycamore Creek of $45 \mu \mathrm{g} / \mathrm{L}$ ), but was over 2-fold higher in the lower bar. The highest concentration of both $\mathrm{NO}_{3}-\mathrm{N}$ and SRP occurred in the lower bar and the lowest in surface water. Conductivity, DOC concentration, and SUVA values were higher in the riparian zone than in other subsystems (Table 1).

[33] Nutrient chemistry varied both within and between bars in parallel with differences in $\mathrm{T}_{\text {med }}$. Nitrate-N and SRP concentrations were both higher in the lower bar than in the upper bar, as was $\mathrm{T}_{\text {med }}$ (Figure 6). As with $\mathrm{T}_{\text {med }}$, there were no significant differences among depths in nutrient concentrations of the upper bar. In the lower bar, again excluding the connected piezometer nest at $280 \mathrm{~m}$, significant differences among depths in nutrient concentrations mirrored those of $\mathrm{T}_{\text {med }}$ (one-way ANOVA for $\mathrm{NO}_{3}-\mathrm{N}: \mathrm{F}=6.70, \mathrm{p}=0.005$, 


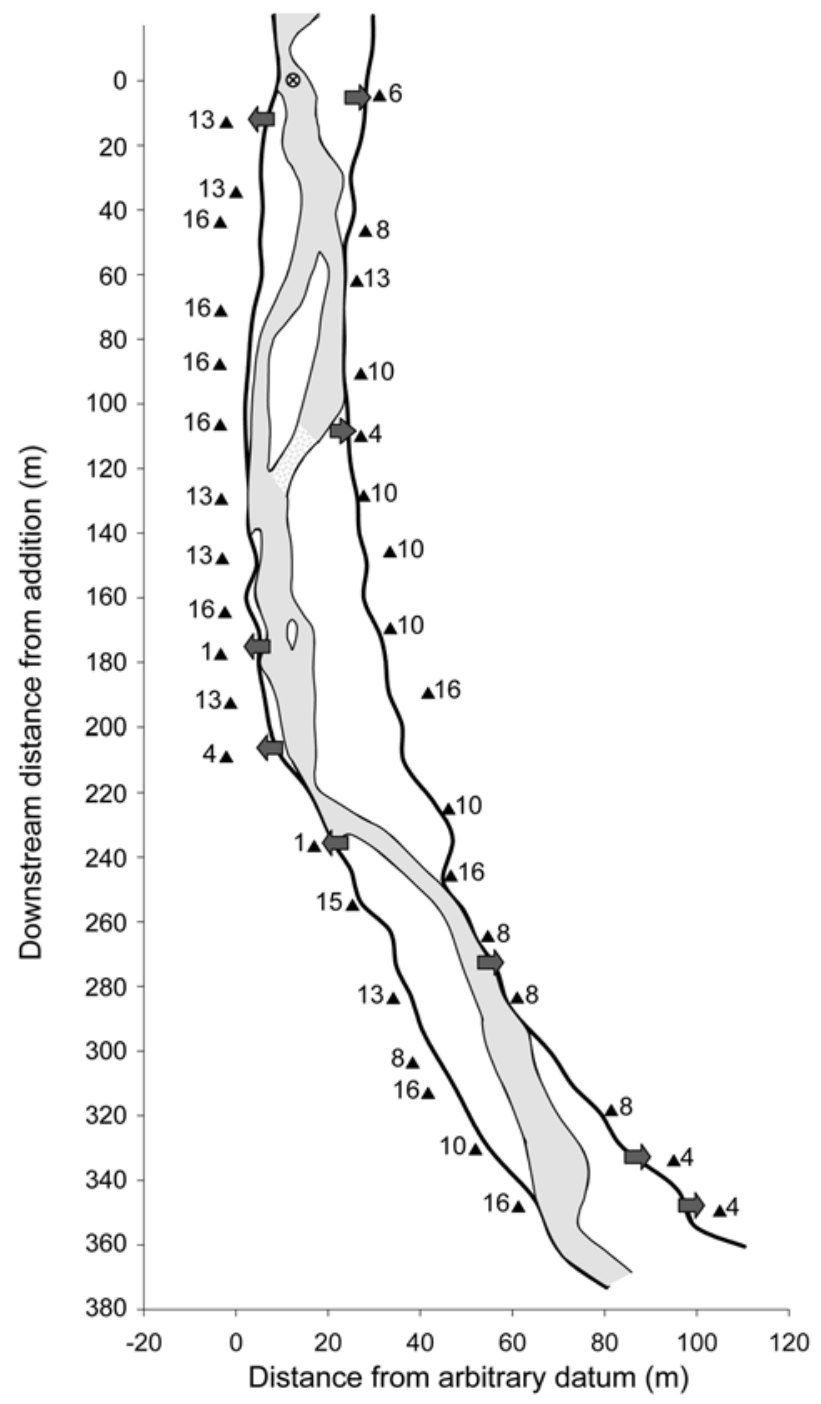

Figure 5. Map of the study area showing median transport times (in days) for riparian piezometers. Block arrows denote likely entry points of stream water into the riparian zone, based upon low travel times.

$\mathrm{df}=2,25$; for SRP: $\mathrm{F}=5.68, \mathrm{p}=0.008, \mathrm{df}=2,31$, with higher concentrations in shallow piezometers.

\section{Discussion}

[34] In this 400-m section of Sycamore Creek at base flow, surface stream, parafluvial and riparian subsystems differed in residence time but were highly connected to one another, surface-subsurface exchange occurred in both directions, and sites of exchange were localized rather than evenly distributed along the reach. These hydrologic characteristics influence the capacity of the whole ecosystem to retain nutrients, as suggested by previous work [Fisher et al., 1998a]. Our study used a longer-term injection of hydrologic tracer than other similar studies, and conclusions are corroborated by water table elevations, $T_{\text {med }}$ for the different subsystems, and longitudinal change in plateau
$\mathrm{Br}^{-}$concentration in all of the subsystems (Figures 1, 4, and 6).

\subsection{Hydrologic Connections}

[35] All piezometers were at least 25\% labeled with added $\mathrm{Br}^{-}$by the end of the 15-d injection, demonstrating the tight hydrologic connection among surface and subsurface water in stream, parafluvial, and riparian subsystems. Further, all subsystems eventually converged on a $\mathrm{Br}^{-}$ concentration of approximately $65-75 \%$ of the surfacewater plateau (Figures 3 and 4). This suggests that as water flowed through the $400-\mathrm{m}$ reach, extensive vertical and lateral mixing occurred among subsystems, and that 25$35 \%$ of the water in the reach at plateau had entered from external sources. Surface water traveled to all piezometers laterally as far as $15 \mathrm{~m}$ from the thalweg and to depths at least $170 \mathrm{~cm}$ below the water table, confirming that the overall direction of water movement in the reach was from the surface stream into parafluvial and riparian zones.

[36] Strong hydrologic connections among subsystems were localized rather than uniformly distributed (Figure 5). Stream water entered the riparian zone between $\mathrm{m} 0$ and $\mathrm{m}$ 30 (both sides), at m 110 (left bank), 180-240 m (right bank), and 310-350 (left bank), and appeared to flow longitudinally between these locations. Surface water moved into gravel bars at specific locations, and in the case of the lower bar, not necessarily from the closest surface water. Other hydrologic studies (in gaining streams) have found that surface water travels to some piezometers lateral to the stream, but only in localized regions due to nearstream flow paths [Triska et al., 1989; Harvey and Bencala, 1993; Triska et al., 1993; Wondzell and Swanson, 1996; Valett et al., 1997; Hill et al., 1998; Wroblicky et al., 1998].

[37] Comparison of downstream dilution patterns in surface water on day 1 and day 15 suggests only two significant inputs from outside the reach (Figure $3 \mathrm{~b}$ ), at sites where drops in plateau concentration occurred on both days ( $\mathrm{m} \mathrm{80-100} \mathrm{and} \mathrm{m} \mathrm{340-360).} \mathrm{The} \mathrm{drop} \mathrm{at} \mathrm{m} \mathrm{80-100}$ was associated with an area of positive VHG (Figure 3a), indicating a vertical influx of unlabeled water from subsurface sediment. We suggest that this water probably originated from upstream, where it infiltrated the sediment and traveled in subsurface flow paths to the study reach. While we cannot be certain of this conclusion, it is supported by previous studies of patterns of stream drying and the lack of off-channel springs in the watershed. It also is consistent with a view of streams in the arid Southwest as primary locations of groundwater recharge rather than discharge [deVries and Simmers, 2002; Blasch et al., 2004]. The drop in plateau concentration at $\mathrm{m} \mathrm{340-360} \mathrm{was} \mathrm{associated} \mathrm{with}$ a tributary junction (Figure 3b). Although there was no surface flow in the tributary during the injection, subsurface flow was likely. The amount of water that entered subsurface subsystems and subsequently returned to the surface stream can be roughly estimated as the difference between $\mathrm{Q}_{\mathrm{L}}$ on days $1(45 \%)$ and $15(28 \%)$. We suggest that this value, $17 \%$ of discharge in the reach, is conservative because some upwelling subsurface water may already have been labeled by day 1 .

[38] Comparisons of tracer concentration at plateau for each subsystem indicated surface-subsurface exchange of labeled surface water along the length of the reach 

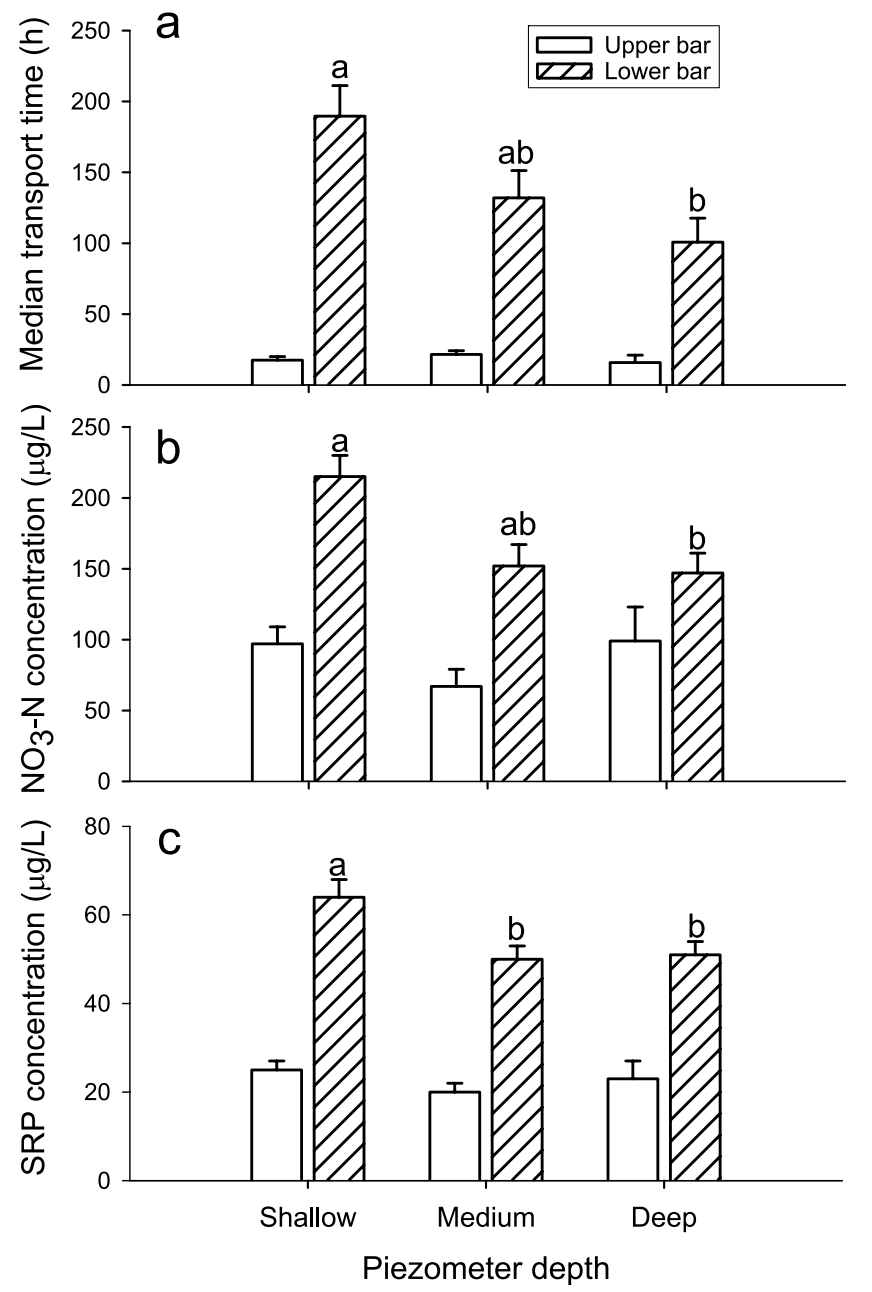

Figure 6. Mean ( \pm standard error) median transport time (a), $\mathrm{NO}_{3}-\mathrm{N}$ concentration (b), and SRP concentration (c) in shallow (30 $\mathrm{cm}$ below water table), medium $(70 \mathrm{~cm}$ below water table), and deep piezometers (110 and $170 \mathrm{~cm}$ below water table) in the upper (white) and lower (hatched) parafluvial gravel bars. Excluded from means was the piezometer nest at $280 \mathrm{~m}$ that was highly connected to the stream (see text). Letters indicate significant differences among depths $(\mathrm{p}<0.05)$ for the lower bar (there were no significant differences for the upper bar).

(Figure 4). In the upper bar, plateau concentration was higher in downstream piezometers than in upstream piezometers. This pattern suggests a mixture of labeled water (from the surface) and unlabeled water (from upstream, subsurface flow paths) near the top of the upper bar, with more labeled water entering the bar further downstream. In the lower bar, no change in plateau concentration with distance was observed, suggesting that if water entered from different locations, it was already equally labeled; or that water inflow from unlabeled compartments was negligible. Day-15 $\mathrm{Br}^{-}$concentration in riparian piezometers increased steadily in a downstream direction, again suggesting that unlabeled subsurface water entered the riparian zone at its upstream end and was enriched with increasing volumes of labeled surface water moving into the riparian zone. Such a pattern implies few inputs to riparian flow paths from upland soils or deep groundwater, and is in marked contrast to mesic, gaining streams, where riparian plateau concentration typically decreases in a downstream direction owing to tracer dilution by unlabeled water entering the reach from these other sources [e.g., Triska et al., 1989, 1993].

[39] Results for stream-riparian connections are consistent with observations made during flood conditions in Sycamore Creek [Martí et al., 2000] and other semiarid streams [e.g., Butturini et al., 2005], and contrast with those found in hydrologic studies of mesic streams [e.g., Chestnut and McDowell, 2000]. Based on changes in riparian water table depth during a 1996 flood at our study site, Martí et al. [2000] concluded that surface water moved rapidly into the riparian zone as surface discharge increased. They suggested that during baseflow, however, most riparian zone water moved longitudinally within the riparian zone. Our data are mostly consistent with this view. Although our baseflow data do indicate lateral inputs from the surface stream to the riparian zone, especially at discrete sites (Figure 5), the dominant direction of flow during baseflow was still longitudinal, whereas the dominant direction during floods was lateral. Slower water movement during baseflow should allow for more processing of nutrients as water moves through different subsystems. In contrast, rapid water movement and little processing of transported materials might be characteristic of periods of flood. However, data on changes in subsurface water velocity during floods would be needed to evaluate this possibility.

\subsection{Variation Within Subsystems}

[40] Despite its apparent uniformity, the parafluvial subsystem harbors large differences in hydrologic characteristics, both between gravel bars and with depth in the lower gravel bar. We therefore conclude that subsurface flow in the parafluvial zone should not be characterized as a single flow path. This conclusion is contrary to our expectation that hydrologic characteristics of this subsystem would be fairly uniform owing to apparent sediment homogeneity. Studies examining both biological and hydrologic processes often simplify hydrology out of necessity, but our results suggest that such simplifications are likely to lead to erroneous interpretations.

[41] Hydraulic gradient was an order of magnitude higher in the upper gravel bar than in the lower bar, enough to explain the equally large difference in velocity (by Darcy's law, velocity is the product of hydraulic gradient and hydraulic conductivity corrected for effective porosity). Others have documented effects of widely varying hydraulic conductivity on hydrologic residence time [Morrice et al., 1997] and thereby on nutrient retention [Valett et al., 1996; Gucker and Boechat, 2004] among different streams or reaches of the same stream. Our data suggest that differences in hydraulic gradient, rather than hydraulic conductivity, explain variation in residence time. What ever the cause, our study is the first to show differences in residence time among depths within a single gravel bar. For most grid points in the lower bar, shallow piezometers were labeled much later (up to $7 \mathrm{~d}$ ) than medium and deep piezometers (e.g., Figures 6 and 7).

[42] We propose that subsurface water entered the upstream end of the lower bar, either from the riparian zone or 


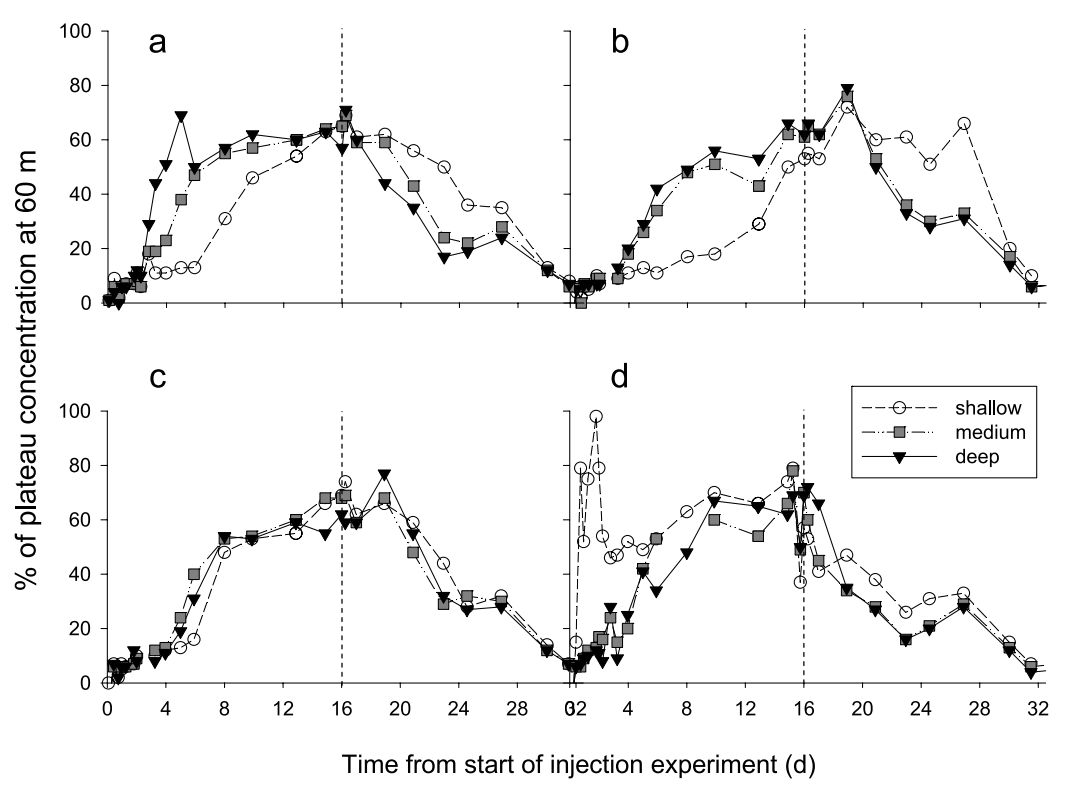

Figure 7. Changes in $\mathrm{Br}^{-}$concentration in four nested piezometers in the lower gravel bar, relative to plateau concentration at $\mathrm{m} 60$ in the surface stream. Each piezometer nest includes one shallow, one medium and one deep piezometer. (a, b) Piezometer nest 2.1 and 3.1 (first digit refers to row and the second to column in the grid; see Figure 1c), on the right (riparian) edge of the bar at m 280 and 290,

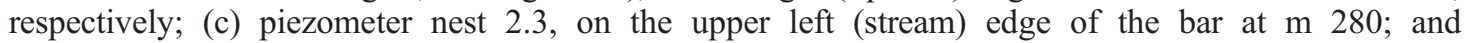
(d) piezometer nest 3.3, on the lower left (stream) edge of the bar at $\mathrm{m} 290$. Injection of $\mathrm{Br}^{-}$tracer (at $\mathrm{m} \mathrm{0}$ ) began on day 0 and was turned off on day 15 (indicated by the vertical dashed line).

from channel sediment upstream, and that coarse sediments (i.e., with higher hydraulic conductivity) buried at depth allowed deeper water to move quickly while shallow water moved very slowly. These coarser sediments may have occurred anywhere along the flow path leading into the lower bar, including the riparian zone, where soils change dramatically with depth due to soil development in shallower layers. Another explanation for the observed differences in transport time among depths is that the piezometers at different depths were on different flow paths, with deep water taking a more direct route than shallow water. In either case, the naive assumption that water moved from the closest surface source into the bar would have resulted in the opposite pattern from what we observed, namely, shallow piezometers would have been labeled before deep piezometers. Unfortunately, subsequent floods prevented us from examining how sediment size and thus hydraulic conductivity changed with depth in the lower bar.

\subsection{Implications for Nutrient Retention}

[43] Riparian, parafluvial and surface subsystems are known to be hydrologically and chemically distinct, and in this respect our findings were consistent with differences noted by other studies (e.g., hydrology [Triska et al., 1989, 1993; Harvey et al., 1996; Wondzell and Swanson, 1996; Morrice et al., 1997] and chemistry [Valett et al., 1990, 1997; McDowell et al., 1992; Holmes et al., 1994a, 1996; Martí et al., 2000; Lewis et al., 2006, 2007]). Differences in $\mathrm{NO}_{3}-\mathrm{N}$ and SRP concentrations among surface water, parafluvial, and riparian zones conformed to expectations based on what is known about the dominant processes in these zones, despite the high hydrologic connectivity among them. Relatively well-oxygenated channel sediment supports aerobic nitrifiers, so $\mathrm{NO}_{3}-\mathrm{N}$ accumulates along flow paths as $\mathrm{N}$ is mineralized [Holmes et al., 1994b; Jones et al., 1995a], whereas $\mathrm{NH}_{4}^{+}$is often the dominant $\mathrm{N}$ ion in frequently anoxic riparian groundwater [Schade et al., 2002; Lewis et al., 2007]. Elevated DOC concentration in the riparian zone relative to other subsystems also has been observed previously [e.g., Chestnut and McDowell, 2000; Martí et al., 2000; Baker et al., 2000; Harms, 2004]. The high chemical complexity of DOC (as measured by SUVA; Table 1) suggests that the source of riparian DOC was terrestrial primary production incorporated into the soils during decomposition [McKnight et al., 2001]. In contrast,

Table 1. Comparison of Chemical Characteristics (Mean \pm 1 SE) Among Subsystems ${ }^{\mathrm{a}}$

\begin{tabular}{|c|c|c|c|c|}
\hline \multirow[b]{2}{*}{ Parameter } & \multirow[b]{2}{*}{ Surface Stream } & \multicolumn{2}{|c|}{ Parafluvial Zone } & \multirow[b]{2}{*}{ Riparian Zon } \\
\hline & & Upper Bar & Lower Bar & \\
\hline Nitrate-N, $\mu \mathrm{g} / \mathrm{L}$ & $12 \pm 1^{\mathrm{a}}$ & $85 \pm 8^{b}$ & $140 \pm 12^{\mathrm{c}}$ & $14 \pm 1^{\mathrm{a}}$ \\
\hline Ammonium-N, $\mu \mathrm{g} / \mathrm{L}$ & $\mathrm{n} / \mathrm{a}$ & $\mathrm{n} / \mathrm{a}$ & $\mathrm{n} / \mathrm{a}$ & $32 \pm 7$ \\
\hline $\mathrm{SRP}, \mu \mathrm{g} / \mathrm{L}$ & $13 \pm 1^{\mathrm{a}}$ & $22 \pm 1^{\mathrm{a}}$ & $50 \pm 2^{\mathrm{b}}$ & $27 \pm 7^{\mathrm{a}, \mathrm{b}}$ \\
\hline $\mathrm{DOC}, \mathrm{mg} / \mathrm{L}$ & $3.5 \pm 0.3^{\mathrm{a}, \mathrm{b}}$ & $4.1 \pm 0.1^{\mathrm{a}}$ & $3.4 \pm 0.04^{\mathrm{b}}$ & $6.2 \pm 0.7^{\mathrm{c}}$ \\
\hline SUVA (UVA*1000/mgDOC) & $10 \pm 0.3^{\mathrm{a}}$ & $9 \pm 0.1^{\mathrm{a}}$ & $10 \pm 0.3^{\mathrm{a}}$ & $18 \pm 4^{\mathrm{b}}$ \\
\hline Conductivity, $\mu \mathrm{S} / \mathrm{cm}$ & $448 \pm 2^{\mathrm{a}}$ & $442 \pm 2^{\mathrm{a}}$ & $443 \pm 2^{\mathrm{a}}$ & $635 \pm 88^{\mathrm{b}}$ \\
\hline
\end{tabular}

${ }^{a}$ Significant differences $(\mathrm{p}<0.05)$ are indicated by unique superscript letters; $\mathrm{n} / \mathrm{a}$, not available. 

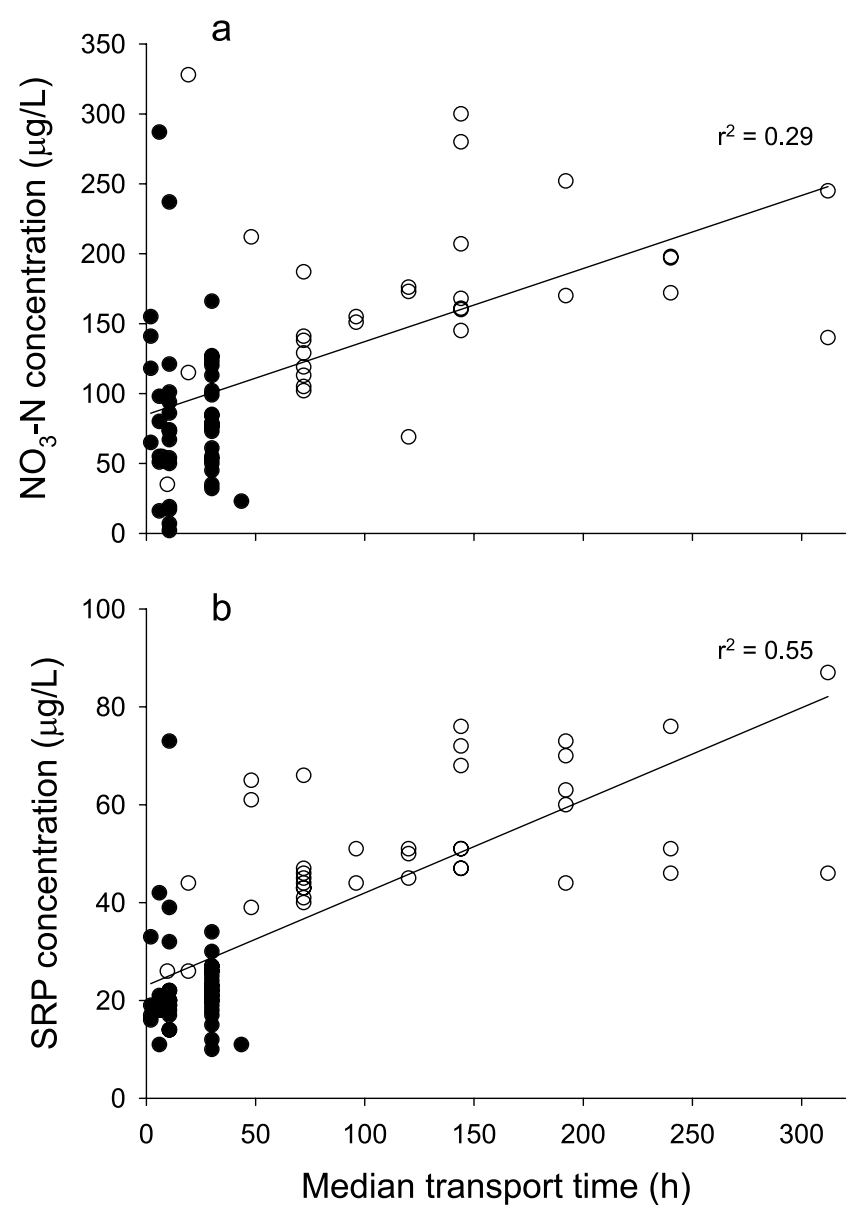

Figure 8. Regression of (a) $\mathrm{NO}_{3}-\mathrm{N}$ and (b) SRP against median transport time, for upper and lower bar piezometers (symbols as in Figure 1). Simple linear regressions are significant $(\mathrm{p}<0.001)$ in both cases.

DOC in surface and subsurface water of the active channel was likely derived from less structurally complex algal material, and had correspondingly lower SUVA. Combining biogeochemical expectations such as these with understanding of hydrologic flow paths from the tracer study should improve our understanding of the source and consequences of biogeochemical differences among and within subsystems.

[44] Nutrient concentration patterns in the two gravel bars allowed us to examine within-subsystem variation in nutrient availability as driven by hydrology. We expected concentrations of $\mathrm{NO}_{3}-\mathrm{N}$ and SRP to increase with residence time (using $\mathrm{T}_{\text {med }}$ as a surrogate) based upon the empirical observation along shorter flow paths that concentrations increase with distance (i.e., the parafluvial zone is a nutrient source region [Holmes et al., 1994a]). Our data confirmed the positive relationship between $\mathrm{T}_{\text {med }}$ and nutrient concentration (Figure 8); thus, higher mean concentrations in the lower bar can be at least partly explained by the longer residence time in that gravel bar.

[45] Both parafluvial and hyporheic zones have been shown to play an important role in whole-stream metabolism and in nutrient recycling [Grimm and Fisher, 1984; Holmes et al., 1994a; Jones et al., 1995a, 1995b; Findlay,
1995; Valett et al., 1996; Mulholland et al., 1997; Jones, 2002]. Recycling of nitrogen from organic to inorganic form may increase algal biomass [Dent and Henry, 1999] and community structure [Henry and Fisher, 2003] and speed recovery after flooding where subsurface water reenters the surface stream [Valett et al., 1994]. Differences in configuration that change hydrologic connections between surface and subsurface sediment potentially change the amount of inorganic $\mathrm{N}$ emerging from subsurface flow paths [Holmes, 1995]. We estimated nutrient flux from gravel bars for the 400-m stream reach to illustrate this effect. We assumed that concentrations of $\mathrm{NO}_{3}^{-}-\mathrm{N}$ and SRP increased linearly with transport time and flow path length in gravel bars (Figure 8). We then considered two hypothetical, 60-m long gravel bars, one with the hydrologic characteristics of the upper bar in our study and the other identical in shape but having the hydrological characteristics of the lower bar. The flux of $\mathrm{NO}_{3}-\mathrm{N}$ from the first gravel bar would be $0.72 \mathrm{~g} / \mathrm{h}$, based on a water flux of $9 \mathrm{~m}^{3} / \mathrm{h}$ (velocity $3 \mathrm{~m} / \mathrm{h}$, width $15 \mathrm{~m}$, depth $1 \mathrm{~m}$, porosity $20 \%$ ) and a concentration of $0.08 \mathrm{~g} / \mathrm{m}^{3}$ (expected $\mathrm{NO}_{3}-\mathrm{N}$ concentration from Figure 8 at $\mathrm{T}_{\text {med }}=$ $20 \mathrm{~h}$ ). In the second case, the bar would have a velocity of $0.3 \mathrm{~m} / \mathrm{h}$ (the velocity of the lower bar) and would produce a much smaller water flux of $0.9 \mathrm{~m}^{3} / \mathrm{h}$, along with a somewhat higher concentration of about $0.15 \mathrm{~g} / \mathrm{m}^{3}$ (expected $\mathrm{NO}_{3}-\mathrm{N}$ concentration from Figure 8 with $\mathrm{T}_{\text {med }}=200 \mathrm{~h}$ ), resulting in a flux of $\mathrm{NO}_{3}-\mathrm{N}$ of $0.14 \mathrm{~g} / \mathrm{h}$, less than a quarter of the first estimate. In this example, although $\mathrm{NO}_{3}-\mathrm{N}$ increases with residence time in channel sediment, it does not increase rapidly enough to overcome the decreased water flux that accompanies longer residence times.

[46] The strength, location and direction of hydrologic exchange within the reach affect flow paths and rates of material transport and thereby whole reach nutrient processing and retention [Fisher et al., 1998a]. The overall direction of water movement from the surface stream into parafluvial and riparian zones implies that these subsystems depend on the surface stream for water and possibly also for organic matter and nutrients, and therefore that processes occurring within the surface stream affect hyporheic, parafluvial, and riparian biology. For instance, riparian trees in arid areas often depend on water from the surface stream for both growth and recruitment [Stromberg and Patten, 1991; Stromberg, 1993]. The source of nutrients for riparian trees has received less attention, although Schade et al. [2005] showed that a fraction of stream-water nitrogen is used by riparian trees in Sycamore Creek during baseflow. This nitrogen source, however, is likely minor in comparison to in situ mineralization [Schade et al., 2002].

[47] In mesic areas, riparian zones are valued for their ability to filter nutrients from water passing laterally from the uplands into the stream channel [Peterjohn and Correll, 1984; Hill, 1996; Hill et al., 2000; Sabater et al., 2003]. In arid areas, although upland water initially enters the stream channel without passing underneath extensive riparian areas, exchange of water between the surface stream and riparian subsurface water may also serve as a filter, removing $\mathrm{NO}_{3}-\mathrm{N}$ as water moves downstream [see also Schade et al., 2005]. The effectiveness of this longitudinal filter will depend on the volume of water that flows from the stream into the riparian zone as well as on riparian zone processes. 
For example, in our study reach if surface water moved uniformly into the riparian zone at a velocity of $0.2 \mathrm{~m} / \mathrm{h}$ across a cross-sectional area $400 \mathrm{~m}$ long on each side and $1 \mathrm{~m}$ deep, the flux of water through the riparian zone would be approximately $160 \mathrm{~m}^{3} / \mathrm{h}$, as compared to $66 \mathrm{~L} / \mathrm{s}$ or about $240 \mathrm{~m}^{3} / \mathrm{h}$ in the surface. Under these assumptions, if riparian zone processing removed all of the $\mathrm{NO}_{3}-\mathrm{N}$ in that water, about $67 \%$ of surface water $\mathrm{NO}_{3}-\mathrm{N}$ flux would be removed by the riparian zone in $400 \mathrm{~m}$. If instead (and more realistically) surface water only entered the riparian zone at localized regions, which we estimated from our study to cover about $10 \%$ of the riparian-channel boundary, the riparian zone could remove only $7 \%$ of surface water $\mathrm{NO}_{3}-\mathrm{N}$ in $400 \mathrm{~m}$. Whether water passed directly from surface into riparian zone or traversed the parafluvial zone before entering the riparian zone would also affect nitrogen retention considerably.

\section{Summary}

[48] We report results from a long-term hydrological tracer experiment quantifying surface-subsurface interactions in a losing stream. Our study clarified baseflow hydrologic connections that have been assumed to exist in losing systems but rarely verified: water moved rapidly from the surface stream into parafluvial and riparian subsystems, but a significant amount returned to the surface stream within the 400-m study reach. Sources of water from outside the system were likely limited to surface and subsurface flow paths upstream of the study reach and tributaries. Connections were localized and discrete, and could in some cases be inferred from surface topography and hydraulic gradient. Chemical characteristics differed among surface water, channel sediment and riparian zone in this losing stream in a manner consistent with differences in hydrologic characteristics and known predominant biogeochemical processes. Within-subsystem variation was also high, particularly in the parafluvial zone, where we had expected fairly homogeneous conditions. This within-system variation may be explained by differences in hydraulic gradient (between gravel bars) but also implies differences in hydraulic conductivity (with depth in a single gravel bar). Substantial exploration of system hydrology is necessary to understand how streams process materials as they move into downstream reservoirs, lakes, or oceans.

[49] Acknowledgments. This research was part of the Lotic Intersite Nitrogen eXperiment (LINX) supported by a National Science Foundation grant (DEB-9628860) to Virginia Tech (subcontract to N.B.G. and E.M. at Arizona State University). A vast number of people loosely associated with Arizona State University provided essential field help. Jennifer Tank provided knowledge and assistance at every turn. Tom Colella orchestrated the chemical analyses and designed the power supply for the pump. We thank the U.S. Forest Service, Tonto National Forest/Mesa Ranger District, for ensuring restricted access to the site during the experiment. H. M. Valett and two anonymous referees provided a thorough review of an earlier version of the manuscript, forcing us to learn more hydrology, for which we thank them. We thank Roy Haggerty and Michael Gooseff for excellent reviews and Roy in particular for extensive discussion of the more recent version of this manuscript. N.B.G. acknowledges support from the Consejo Superior de Investigaciones Científicas (CSIC) while on sabbatical at the Centre d'Estudis Avançats de Blanes, during final revisions. This paper is dedicated to the memory of C. Lisa Dent, whose talent, energy, and friendship are sorely missed.

\section{References}

Baker, M. A., H. M. Valett, and C. N. Dahm (2000), Organic carbon supply and metabolism in a shallow groundwater ecosystem, Ecology, 81, $3133-3148$

Blasch, K., T. P. A. Ferre, M. Bailey, J. Cordova, and J. Hoffman (2004), Processes controlling recharge beneath ephemeral streams in southern Arizona, in Groundwater Recharge in a Desert Environment: The Southwestern United States, edited by J. F. Hogan, F. M. Phillips, and B. R. Scanlon, p. 294, AGU, Washington, D. C.

Butturini, A., S. Bernal, E. Nin, C. Hellin, L. Rivero, S. Sabater, and F. Sabater (2003), Influences of the stream groundwater hydrology on nitrate concentration in unsaturated riparian area bounded by an intermittent Mediterranean stream, Water Resour. Res., 39(4), 1110, doi:10.1029/ 2001 WR001260.

Butturini, A., S. Bernal, and F. Sabater (2005), Modeling storms events to investigate the influence of the stream-catchment interface zone on stream biogeochemistry, Water Resour. Res., 41, W08418, doi:10.1029/ 2004WR003842.

Chestnut, T. J., and W. H. McDowell (2000), C and N dynamics in the riparian and hyporheic zones of a tropical stream, Luquillo Mountains, Puerto Rico, J. N. Am. Benthol. Soc., 19, 199-214.

Clement, J. C., R. M. Holmes, B. J. Peterson, and G. Pinay (2003), Isotopic investigation of denitrification in a riparian ecosystem in western France, J. Appl. Ecol., 40, 1035-1048.

Dent, C. L., and N. B. Grimm (1999), Spatial heterogeneity of stream water nutrient concentrations over successional time, Ecology, 80, 2283-2298.

Dent, C. L., and J. C. Henry (1999), Modelling nutrient-periphyton dynamics in streams with surface-subsurface exchange, Ecol. Modell., $122,97-116$

deVries, J. J., and I. Simmers (2002), Groundwater recharge: an overview of processes and challenges, Hydrogeol. J., 10, 5-17.

Fetter, C. W. (1994), Applied Hydrogeology, 3rd ed., Macmillan, New York. Findlay, S. (1995), Importance of surface-subsurface exchange in stream ecosystems: the hyporheic zone, Limnol. Oceanogr., 40, 159-164.

Fisher, S. G., N. B. Grimm, E. Martí, and R. Gomez (1998a), Hierarchy, spatial configuration, and nutrient cycling in a desert stream, Aust. J. Ecol., 23, 41-52.

Fisher, S. G., N. B. Grimm, E. Martí, R. M. Holmes, and J. B. Jones Jr. (1998b), Material spiraling in stream corridors: a telescoping ecosystem model, Ecosystems, 1, 19-34.

Gooseff, M. N., R. O. Hall, and J. L. Tank (2007), Relating transient storage to channel complexity in streams of varying land use in Jackson Hole, Wyoming, Water Resour. Res., 43, W01417, doi:10.1029/ 2005 WR004626.

Grimm, N. B., and S. G. Fisher (1984), Exchange between surface and interstitial water: implications for stream metabolism and nutrient cycling, Hydrobiologia, 111, 219-228.

Grimm, N. B., and S. G. Fisher (1986), Nitrogen limitation in a Sonoran Desert stream, J. N. Am. Benthol. Soc., 5, 2-15.

Gucker, B., and I. G. Boechat (2004), Stream morphology controls ammonium retention in tropical headwaters, Ecology, 85, 2818-2827.

Harms, T. K. (2004), Impacts of plant community patchiness, vertical gradients, and temporal variability on microbial nitrogen transformations in a semi-arid riparian zone, M. S. thesis, Ariz. State Univ., Tempe.

Harvey, J. W., and K. E. Bencala (1993), The effect of streambed topography on surface-subsurface water exchange in mountain catchments, Water Resour. Res., 29, 89-98.

Harvey, J. W., B. J. Wagner, and K. E. Bencala (1996), Evaluating the reliability of the stream tracer approach to characterize stream-subsurface water exchange, Water Resour. Res., 32, 2441-2451.

Henry, J. C., and S. G. Fisher (2003), Spatial segregation of periphyton communities in a desert stream: causes and consequences for $\mathrm{N}$ cycling, J. N. Am. Benthol. Soc., 22, 511-527.

Hill, A. R. (1996), Nitrate removal in stream riparian zones, J. Environ. Oual., 25, 743-755.

Hill, A. R., C. F. Labadia, and K. Sanmugadas (1998), Hyporheic zone hydrology and nitrogen dynamics in relation to the streambed topography of a N-rich stream, Biogeochemistry, 42, 285-310.

Hill, A. R., K. J. Devito, S. Campagnolo, and K. Sanmugadas (2000), Subsurface denitrification in a forest riparian zone: interactions between hydrology and supplies of nitrate and organic carbon, Biogeochemistry, 51, 193-223.

Holmes, R. M. (1995), Parafluvial nutrient dynamics in a desert stream ecosystem, Ph.D. dissertation, Ariz. State Univ., Tempe.

Holmes, R. M., S. G. Fisher, and N. B. Grimm (1994a), Nitrogen dynamics along parafluvial flowpaths: importance to the stream ecosystem, in Proceedings of the Second International Conference on Groundwater Ecology, edited by J. A. Stanford and H. M. Valett, pp. 47-56, Am. Water Resour. Assoc., Bethesda, Md. 
Holmes, R. M., S. G. Fisher, and N. B. Grimm (1994b), Parafluvial nitrogen dynamics in a desert stream ecosystem, J. N. Am. Benthol. Soc., 13, $468-478$

Holmes, R. M., J. B. Jones Jr., S. G. Fisher, and N. B. Grimm (1996), Denitrification in a nitrogen-limited stream ecosystem, Biogeochemistry, $33,125-146$.

Jones, J. B. (2002), Groundwater controls on nutrient cycling in a Mojave Desert stream, Freshwater Biol., 47, 971-983.

Jones, J. B., Jr., S. G. Fisher, and N. B. Grimm (1995a), Nitrification in the hyporheic zone of a desert stream ecosystem, J. N. Am. Benthol. Soc., 14, $249-258$

Jones, J. B., Jr., S. G. Fisher, and N. B. Grimm (1995b), Vertical hydrologic exchange and ecosystem metabolism in a Sonoran Desert stream, Ecology, 76, 942-952.

Korshin, G. V., C. Li, and M. M. Benjamin (1997), Monitoring the properties of natural organic matter through UV spectroscopy: a consistent theory, Water Resour., 31, 1787-1795.

Lee, D. R., and J. A. Cherry (1978), A field exercise on groundwater flow using seepage meters and mini-piezometers, J. Geol. Educ., 27, 6-10.

Lewis, D. B., J. D. Schade, A. K. Huth, and N. B. Grimm (2006), The spatial structure of variability in a semi-arid, fluvial ecosystem, Ecosystems, 9, 386-397.

Lewis, D. B., N. B. Grimm, T. K. Harms, and J. D. Schade (2007), Subsystems, flowpaths, and the spatial variability of nitrogen in a fluvial ecosystem, Landscape Ecol., doi:10.1007/s10980-007-9078-6.

Martí, E., S. G. Fisher, J. D. Schade, and N. B. Grimm (2000), Flood frequency, arid land streams and their riparian zones, in Streams and Ground Waters, edited by J. B. Jones Jr. and P. J. Mulholland, pp. 111-136, Academic, San Diego, Calif.

McClain, M. E., et al. (2003), Biogeochemical hot spots and hot moments at the interface of terrestrial and aquatic ecosystems, Ecosystems, 6, 301312.

McDowell, W. H., W. B. Bowden, and C. E. Asbury (1992), Riparian nitrogen dynamics in two geomorphologically distinct tropical rain fores watersheds: subsurface solute patterns, Biogeochemistry, 18, 53-75.

McKnight, D. M., E. W. Boyer, P. K. Westerhoff, P. T. Doran, T. Kulbe, and D. T. Andersen (2001), Spectrofluorometric characterization of dissolved organic matter for indication of precursor organic material and aromaticity, Limnol. Oceanogr., 46, 38-48.

Morrice, J. A., H. M. Valett, C. N. Dahm, and M. E. Campana (1997), Alluvial characteristics, groundwater-surface water exchange and hydrologic retention in headwater streams, Hydrol. Processes, 11, 1-15.

Mulholland, P. J., E. R. Marzolf, J. R. Webster, D. R. Hart, and S. P. Hendricks (1997), Evidence that hyporheic zones increase heterotrophic metabolism and phosphorus uptake in forest streams, Limnol. Oceanogr., $42,443-451$

Murphy, J., and J. P. Riley (1962), A modified single solution method for the determination of phosphate in natural waters, Anal. Chim. Acta, 27, $31-36$.

Palmer, M. A., and N. L. Poff (1997), The influence of environmental heterogeneity on patterns and processes in streams, J. N. Am. Benthol. Soc., 16, 169-173.

Peterjohn, W. T., and D. L. Correll (1984), Nutrient dynamics in an agricultural watershed: observations on the role of a riparian forest, Ecology, $65,1466-1475$.

Pinay, G., C. Ruffinoni, S. M. Wondzell, and F. Gazelle (1998), Change in groundwater nitrate concentration in a large river floodplain: denitrification, uptake, or mixing?, J. N. Am. Benthol. Soc., 17, 179-189.

Runkel, R. L. (2002), A new metric for determining the importance of transient storage, J. N. Am. Benthol. Soc., 21, 529-543.

Sabater, S., et al. (2003), Nitrogen removal by riparian buffers along a European climatic gradient: Patterns and factors of variation, Ecosystems, $6,20-30$

Schade, J. D., S. G. Fisher, N. B. Grimm, and J. A. Seddon (2001), The influence of a riparian shrub on nitrogen cycling in a Sonoran Desert stream, Ecology, 82, 3363-3376.
Schade, J. D., E. Martí, J. R. Welter, S. G. Fisher, and N. B. Grimm (2002), Sources of nitrogen to the riparian zone of a desert stream: implications for riparian vegetation and nitrogen retention, Ecosystems, 5, 68-79.

Schade, J. D., J. R. Welter, E. Martí, and N. B. Grimm (2005), Hydrologic exchange and $\mathrm{N}$ uptake by riparian vegetation in an arid-land stream, $J$. $N$. Am. Benthol. Soc., 24, 19-28.

Solorzano, L. (1969), Determination of ammonium in natural water by the phenolhypochlorite method, Limnol. Oceanogr., 14, 799-801.

Stanley, E. H., and H. M. Valett (1992), Interaction between drying and the hyporheic zone of a desert stream ecosystem, in Climate Change and Freshwater Ecosystems, edited by P. Firth and S. G. Fisher, pp. 234-249, Springer, New York.

Stromberg, J. C. (1993), Fremont cottonwood-gooding willow riparian forests: a review of their ecology, threats, and recovery potential, J. Ariz. Nev. Acad. Sci., 26, 97-109.

Stromberg, J. C., and D. T. Patten (1991), Instream flow requirements for cottonwoods at Bishop Creek, Inyo County, California, Rivers, 2, 1-11.

Triska, F. J., V. C. Kennedy, R. J. Avanzino, G. W. Zellweger, and K. E. Bencala (1989), Retention and transport of nutrients in a 3rd-order stream in northwestern California: hyporheic processes, Ecology, 70, $1893-$ 1905

Triska, F. J., J. H. Duff, and R. J. Avanzino (1993), Patterns of hydrological exchange and nutrient transformation in the hyporheic zone of a gravel bottom stream: examining terrestrial-aquatic linkages, Freshwater Biol., $29,259-274$

Valett, H. M., S. G. Fisher, and E. H. Stanley (1990), Physical and chemical characteristics of the hyporheic zone of a Sonoran Desert stream, J. N Am. Benthol. Soc., 9, 201-215.

Valett, H. M., S. G. Fisher, N. B. Grimm, and P. Camill (1994), Vertical hydrologic exchange and ecological stability of a desert stream ecosystem, Ecology, 75, 548-560.

Valett, H. M., J. A. Morrice, C. N. Dahm, and M. E. Campana (1996), Parent lithology, surface-groundwater exchange, and nitrate retention in headwater streams, Limnol. Oceanogr., 41, 333-345.

Valett, H. M., C. N. Dahm, M. E. Campana, J. A. Morrice, M. A. Baker, and C. S. Fellows (1997), Hydrologic influences on groundwater-surface water ecotones: heterogeneity in nutrient composition and retention, $J . N$. Am. Benthol. Soc., 16, 239-247.

Ward, J. V. (1989), The four-dimensional nature of lotic ecosystems, J. N. Am. Benthol. Soc., 8, 2-8.

Wiens, J. A. (2002), Riverine landscapes: taking landscape ecology into the water, Freshwater Biol., 47, 501-515.

Wondzell, S. M., and F. J. Swanson (1996), Seasonal and storm dynamics of the hyporheic zone of a 4th-order mountain stream. I: Hydrologic processes, J. N. Am. Benthol. Soc., 15, 3-19.

Wood, E. D., F. A. J. Armstrong, and F. A. Richards (1967), Determination of nitrate in seawater by cadmium-copper reduction to nitrite, J. Mar Biol. Assoc. U. K., 46, 23-31.

Wroblicky, G. J., M. E. Campana, H. M. Valett, and C. N. Dahm (1998), Seasonal variation in surface-subsurface water exchange and lateral hyporheic area of two stream-aquifer systems, Water Resour. Res., 34, $317-328$.

J. W. Edmonds, Department of Marine Sciences, University of Georgia, Athens, GA 30602-3636, USA. (edmonds@uga.edu)

N. B. Grimm, School of Life Sciences, Arizona State University, Box 874501, Tempe, AZ 85287-4501, USA. (nbgrimm@asu.edu)

J. C. Henry, 5105 Clear Run Drive, Wilmington, NC 28403, USA (jchenry123@yahoo.com)

E. Martí, Centre d'Estudis Avançats de Blanes (CSIC), Accès a la Cala St. Francesc 14, 17300 Blanes, Spain. (eugenia@ceab.csic.es)

J. R. Welter, College of St. Catherine, 2004 Randolph Avenue, \#4205, Saint Paul, MN 55105, USA. (jrwelter@stkate.edu) 